\title{
Improving the Performance of Milling of Titanium Alloys Using the Atomization-Based Cutting Fluid Application System
}

\author{
Surojit Ganguli, Shiv. G. Kapoor ${ }^{\mathrm{a}, *}$ \\ ${ }^{a}$ Department of Mechanical Science and Engineering, University of Illinois, Urbana, IL
}

\begin{abstract}
The research presented in this paper investigates the effectiveness of the atomization-based cutting fluid (ACF) spray system in end-milling of titanium alloy, Ti-6Al-4V. To that end, the study has been conducted in two phases. In the first phase, experiments have been carried out to select suitable spray parameters. A numerical model of the ACF spray system has also been developed to gain a physics-based understanding of the cutting fluid film formation on a rotating tool surface and its role in providing cooling and lubrication at the cutting interface. In the second phase, experiments have been conducted to compare the machinability of titanium for different cutting fluid application methods, viz., dry cutting, flood cooling and ACF spray system, on the basis of five machinability parameters, including, tool life, tool wear, cutting forces, surface roughness and chip morphology. Experimental results show that the application of the ACF spray system results in uniform tool flank wear, lower cutting forces and higher surface finish and the tool life extends upto $75 \%$ over flood cooling. Additionally, chip morphology analysis reveals that using ACF spray system leads to the formation of shorter and thinner chips, as compared to those when flood cooling is used.
\end{abstract}

\footnotetext{
${ }^{*}$ Corresponding author

Email address: sgkapoor@illinois.edu (Shiv. G. Kapoor)
}

Preprint submitted to Journal of Manufacturing Processes

January 18, 2016

(C) 2016. This manuscript version is made available under the Elsevier user license http://www.elsevier.com/open-access/userlicense/1.0/ 
Keywords: Atomized droplets, Titanium alloy, Milling, Machining

performance, Sustainability

\section{Introduction}

Titanium alloys are considered difficult-to-machine materials because of poor thermal conductivity and low elongation to break ratio, which makes it difficult to dissipate the heat generated during the cutting process[1, 2]. High temperatures generated in the cutting zone lead to plastic deformation of the tool and an increase in chemical reactivity of titanium with the tool resulting in rapid tool wear and catastrophic tool failure $[3,4]$. Hence, it is imperative to find effective methods to cool the cutting zone. Recently, it has been shown that an atomization-based cutting fluid (ACF) spray system can effectively cool and lubricate the cutting zone during turning of Ti-6Al-4V, leading to significant improvement in machinability of titanium alloys [5]. However, the efficacy of the ACF spray system is yet to be tested for other machining operations that are different from turning, like milling.

There are three main challenges unique to milling when an ACF spray system is used. First, the droplet impingement dynamics gets significantly influenced by the presence of a rotating cutting tool. Second, due to the complex geometry of the milling tool, the droplets after impingement could lead to the formation of a non-uniform fluid film. Third, the film formed on an end mill tool would have highest momentum near the point of impact and low momentum farther away from it. It would be quite challenging to achieve the film momentum that would ensure effective film penetration at the tool-chip interface all throughout the time the cutting edge of tool is engaged with the work piece. Also, milling is an intermittent cutting process that gets affected by thermal shock caused by cutting fluid[6].

Many coolant application methods, including flood cooling, minimum quan- 
tity lubrication (MQL) and cooling gas methods have been employed in milling titanium alloys and the limitations of each of these methods, have been stated elsewhere[7, 8]. Jun et al.[9] recently used an atomization-based cutting fluid (ACF) system for micro-end milling of metals, such as: 1018 steel and Al 7075. The ACF system was found to reduce cutting forces, improve tool life by 3 times over flood cooling, even at feed rates where ploughing and rubbing is dominant and lower the temperature of the cutting zone remarkably more than what could be achieved while using dry and flood cooling methods. However, the success of ACF spray system in macro-scale milling is not guaranteed because the cutting interface that is generated during macro-scale milling, because of greater feed and depth of cut, is larger than the one generated in micro-scale milling. As a result the liquid film could easily get evaporated before it would reach the entire cutting interface.

A few theoretical studies have also been conducted that focus specifically on the nature of interaction between droplets produced by an ACF spray and a rotating surface. Ghai et al.[10] modeled droplet spreading on a rotating surface with an aim to design an efficient atomization-based cutting fluid (ACF) system for micro-turning processes. Boughner et al.[11] developed a probabilistic model to study the rate of micro-film formation on a rotating cylindrical surface due to an atomization-based cooling system. The model was used to evaluate the relative importance of different spray parameters on liquid film formation. However, the model is two-dimensional and assumes droplet impingement only on a dry surface.

The objective of this study is to experimentally evaluate the effectiveness of the ACF spray system in end-milling of a titanium alloy, Ti-6Al-4V. Experiments have been conducted in two phases. During first phase, experiments are conducted to study various combinations of spray parameters that affect the machinability of Ti-6Al-4V and select the one which has the least cutting forces. In the second phase, machining experiments are conducted, using the spray pa- 
rameters selected in phase one, to assess the machinability of titanium alloy for different cutting fluid application methods, viz., ACF system, flood cooling and dry cutting, as well as for different machining conditions.

The rest of the paper is organized as follows. Section 2 presents the details of the ACF spray unit used for this study. Also, this section contains the review on dynamics of single droplet impingement and highlights the spray parameters that influence the outcome of droplets impinging on a surface. In section 3 , a detailed description of the experimental setup and design of experiments used for this study is presented. Section 4 presents the results from the experiments and a thorough analysis of the experimental observations. Specific conclusions are presented in Section 5 .

\section{ACF Spray System}

The ACF spray unit used during milling of Ti-6Al-4V is shown in Fig.1 [12]. The system consists of: (i) an ultrasonic-based atomizer; (ii) cutting fluid reservoir with a delivery tube; (iii) nozzle unit consisting coaxially-assembled outer droplet and inner gas nozzles; and (iv) high-pressure gas delivery tube for the nozzle-spray unit. The ultrasonic atomizer used for this study is of the type of NS130K50S316, which vibrates at a frequency of $130 \mathrm{kHz}$ and generates atomized droplets having mean diameter of $11.8 \mu \mathrm{m}$. Once the fluid is atomized, the micro-size droplets move forward through the outer droplet nozzle. The highvelocity gas flowing through the gas nozzle entrains these droplets to produce a focused axisymmetric spray jet that is employed in the cutting zone during machining. The exit diameters of the droplet nozzle and the high-velocity gas nozzle are designed to be $18.8 \mathrm{~mm}$ and $1.6 \mathrm{~mm}$, respectively. Both nozzles are considered to have a convergence slope of $40^{\circ}$ and $0.75^{\circ}$, respectively, and the gas nozzle was placed $5 \mathrm{~mm}$ inside the droplet nozzle exit point in order to avoid divergence of droplets[5]. 


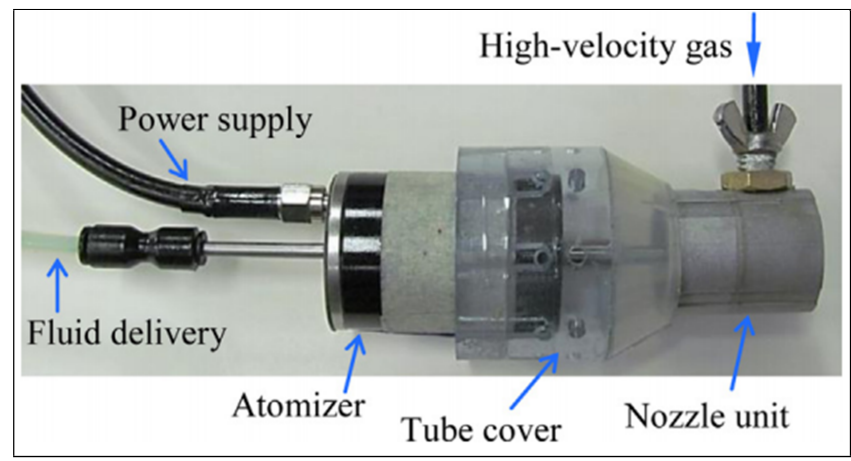

Figure 1: Photograph of the ACF spray unit [12]

The cutting fluid is supplied to the atomizer through a delivery tube and the flow rate is fixed in the range of $8-9 \mathrm{ml} / \mathrm{min}$. The droplet carrier gas used for this study is a mixture of air and carbon dioxide $\left(\mathrm{CO}_{2}\right)$. The primary reason for using $\mathrm{CO}_{2}$ in the mixture is that when it is delivered from a pressurized cylinder it cools down to significantly lower temperatures of $-1{ }^{\circ} \mathrm{C}$ for $9 \mathrm{psi}$ and $-3{ }^{\circ} \mathrm{C}$ for $15 \mathrm{psi}$. When $\mathrm{CO}_{2}$ under such conditions is mixed with air, the mixture attains a temperature in the range of $8-10{ }^{\circ} \mathrm{C}$ and this low temperature is effective in cooling the cutting zone.

The behavior of droplets upon impinging a surface, depends on four specific spray parameters, viz., pressure level of droplet carrier gas, fluid flow rate, droplet impingement angle $(\theta)$, and spray distance, as shown in Fig.2. In ad-

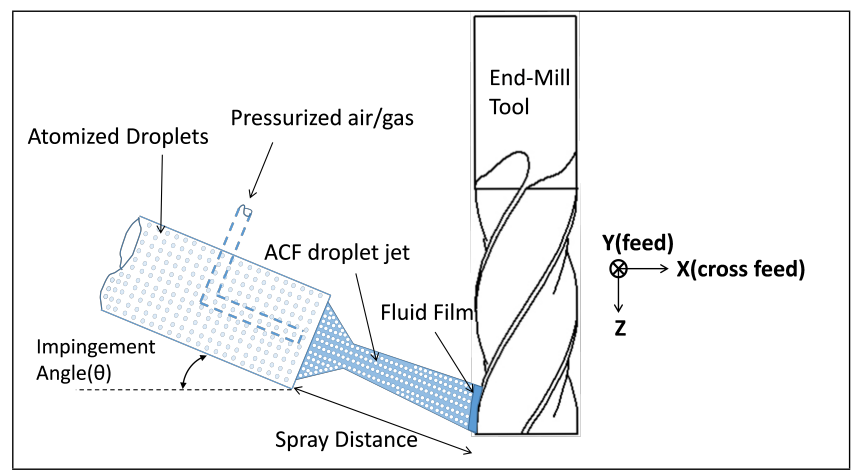

Figure 2: ACF spray system in milling setup 
dition, the droplet diameter $\left(\mathrm{d}_{0}\right)$ and normal velocity component $\left(\mathrm{u}_{\mathrm{o}}\right)$ of the incident droplet, liquid dynamic viscosity $(\mu)$, liquid density $(\rho)$ and the liquid surface tension $(\sigma)$ impact the droplet impingement dynamics[13]. The condition of the receiving surface, such as the film thickness for a wet surface also plays a major role in deciding the fate of the impinging droplets. The non-dimensional numbers that are used to characterize the outcome of droplet impingement on a surface are given by[13]:

$$
\begin{array}{r}
W_{e}=\frac{\rho u_{0}^{2} d_{0}}{\sigma}, R e=\frac{\rho u_{0} d_{0}}{\mu}, O h=\frac{\mu}{\sqrt{d_{0} \sigma \rho}} \\
K_{m}=\left(O h^{-2 / 5} W e\right)^{5 / 8}, K_{y}=u_{0}\left(\frac{\rho}{\sigma}\right)^{1 / 4}\left(\frac{\rho}{\mu}\right)^{1 / 8} f^{-3 / 8}
\end{array}
$$

where We is the Weber Number, Re is the Reynolds number and Oh is the Ohnesorge number. Based on the values of above non-dimensional numbers, four impingement regimes have been identified for droplet-wall and droplet-film interaction phenomenon. The stick regime occurs for $\mathrm{We}<5$, rebounding regime for $5<\mathrm{We}<10$, spreading regime for $\mathrm{We}>10$ and the final regime is splashing. However, the Weber number alone is not sufficient for defining the transition criteria for splashing regime[9]. The droplets would spread if and only if $K_{m}$ $<57.7$ and $K_{y}<17$, where $\mathrm{f}$ in the expression of $K_{y}$ is the frequency of droplet impact. For effective removal of heat from the cutting zone, it is crucial that the droplets are in the spreading regime and are able to access the tool-chip and tool-surface interfaces.

\section{Experimental Setup and Procedure}

A CNC milling machine (OKUMA MC-4VAE) was used for milling experiments. The ACF spray unit was mounted on a metallic frame, as shown in Fig.3. The relative position of the ACF spray unit with respect to tool feed direction is an important parameter, especially for the case when only one set 
of nozzle is used. As seen in Fig.4, there are the three possible angular positions, denoted by $\alpha$, in which the spray unit could be placed. For the spray unit an angle of $135^{\circ}$ was preferred over that of $45^{\circ}$ because Lacalle et al.[14] reported that at an angle of $45^{\circ}$, the cutting fluid is not able to penetrate completely in the tool edges because of the interference produced between the cooling jet and the metal chips that are generated during the machining process. For the present study the value of impingement angle $(\theta)$, as shown in Fig. 2, was fixed at $30^{\circ}$ for all the experiments.

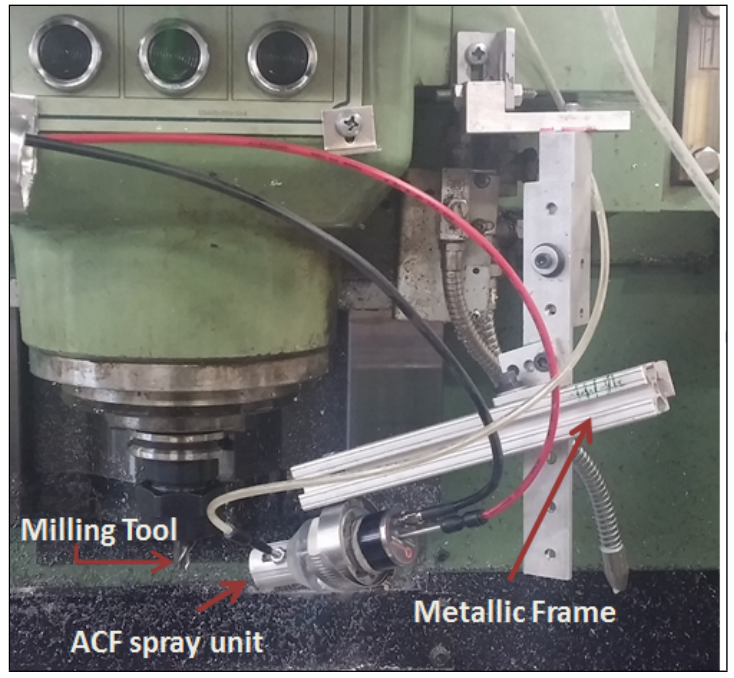

Figure 3: Experimental setup of the ACF spray unit

The end-mill tool used for conducting experiments in this study is an uncoated carbide end mill and the geometry is set as follows: four flutes, $10 \mathrm{~mm}$ mill diameter, and $30^{\circ}$ helix angle. National Instrument data acquisition system (SCB-68), integrated with the LabVIEW software is used to capture cutting force data from the Kistler 3-component force dynamometer (type 9265B), at a sampling frequency of $20 \mathrm{kHz}$. Water soluble cutting fluid S-1001 at $10 \%$ dilution is used as the cutting fluid. The thermo-physical properties of $10 \%$ S-1001 are: Surface Tension $=41[\mathrm{mN} / \mathrm{m}]$, Density $=1003\left[\mathrm{~kg} / \mathrm{mm}^{3}\right]$, Viscosity $=1.22[\mathrm{cP}]$ and Thermal conductivity $=0.53[\mathrm{~W} / \mathrm{mK}]$. The mixture of water 


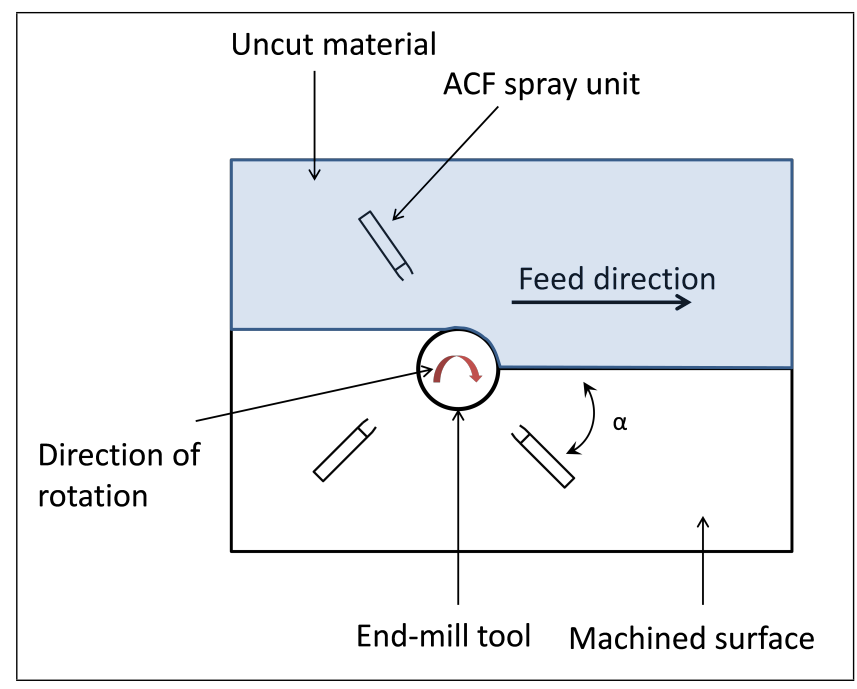

Figure 4: Position of ACF spray unit in relation to feed direction

and cutting fluid is prepared keeping in mind that a cutting fluid with high viscosity and low surface tension is preferable for better lubricity[5].

The first phase of experiments are conducted to study the effect of spray parameters on the cutting forces. The spray parameters that are varied in this study are spray distance and the inlet pressure of the droplet carrier gas. The velocity of the droplet carrier gas at different distances from the gas nozzle is measured by a pitot-static tube (type PSA-"a").

A $2^{2}$ full factorial design is used to access the different combinations of spray parameters as shown in Table 1 . The values of the droplet carrier gas velocity, $\left(u_{g}\right)$, at the end-mill tool for different combinations of spray distance and pressure level are also shown in Table 1. In order to ensure that the selected spray parameters would produce droplets in the spreading regime, the nondimensional numbers, viz., We, $\mathrm{K}_{\mathrm{y}}$ and $\mathrm{K}_{\mathrm{m}}$ are calculated. For calculating the non-dimensional numbers, normal gas velocity $\left(u_{o}\right)$, which is the component of $u_{\mathrm{g}}$ perpendicular to the end-mill tool axis, is required and it is obtained by taking the product of $u_{g}$ with the cosine of the droplet impingement angle $(\theta)$. 
As can be seen from these non-dimensional numbers, the impinging droplets on the end-mill tool would be in the spreading regime (We $>10, K_{m}<57.7$ and $\left.K_{y}<17\right)$. For each combination of spray parameters mentioned in Table 1, a new tool is used to end-mill titanium alloy for a single pass, having a length of $150 \mathrm{~mm}$. Machining conditions for these experiments are: spindle speed 1500 RPM, ADOC $0.5 \mathrm{~mm}$, RDOC $2 \mathrm{~mm}$ and feed/tooth (f) $0.1 \mathrm{~mm} /$ tooth. Each experiment is repeated three times and average peak-to-valley cutting forces for 100 revolutions for each of these three trials are calculated.

Table 1: Values of different non-dimensional numbers at given ACF spray conditions

\begin{tabular}{|l|l|lr|l|l|l|l|l|l|}
\hline Test & $\theta\left[^{\circ}\right]$ & $\begin{array}{l}\text { Spray } \\
\text { tance, } \\
{[\mathrm{mm}]}\end{array}$ & $\mathrm{x}_{1}$ & $\begin{array}{l}\text { Pressure, } \\
\mathrm{x}_{2}[\mathrm{psi}]\end{array}$ & $\mathrm{u}_{\mathrm{g}}[\mathrm{m} / \mathrm{s}]$ & $\mathrm{u}_{\mathrm{o}}[\mathrm{m} / \mathrm{s}]$ & We & $\mathrm{K}_{\mathrm{y}}$ & $\mathrm{K}_{\mathrm{m}}$ \\
\hline $\mathrm{T} 1$ & 30 & 40 & 9 & 27 & 23 & 160 & 2.2 & 49.3 \\
\hline $\mathrm{T} 2$ & 30 & 60 & 9 & 14 & 12 & 39 & 1.15 & 21.7 \\
\hline $\mathrm{T} 3$ & 30 & 40 & 15 & 33 & 30.3 & 269 & 2.8 & 56.8 \\
\hline $\mathrm{T} 4$ & 30 & 60 & 15 & 25 & 21.6 & 137 & 2.05 & 44.8 \\
\hline
\end{tabular}

In phase 2, the tool-life experiments are conducted at four machining conditions, M1-M4, as shown in Table 2. The tool failure criteria are determined by ISO 8688-2[15]: (1) average flank wear $=0.3 \mathrm{~mm}$ (average of all cutting edges), (2) maximum flank wear $=0.5 \mathrm{~mm}$ (on any of the cutting edges), (3) chipping/flaking or fracture of any of the cutting edges. Using the Quadra-Check 300 optical microscope, the total flank wear is measured and photographs of the tool flank faces are taken. Average and maximum surface roughness $\left(R_{a}\right)$ and $\left(R_{z}\right)$, respectively, are measured for the machined surface using a portable surface roughness tester, SR100, having a cutoff length of $0.76 \mathrm{~mm}$. Surface roughness measurements are first made after cutting $0.9 \mathrm{~m}$ ( 6 passes $)$ and then at intervals of $0.6 \mathrm{~m}$, until the tool failed. 
Table 2: Experimental machining parameters

\begin{tabular}{|l|l|l|l|l|}
\hline & M1 & M2 & M3 & M4 \\
\hline Spindle Speed [RPM] & 1500 & 1500 & 1500 & 1500 \\
\hline Axial Depth of Cut [mm] (ADOC) & 0.5 & 1 & 0.5 & 1 \\
\hline Radial Depth of Cut [mm] (RDOC) & 2 & 2 & 2 & 2 \\
\hline Feed/Tooth [mm/tooth] (FR) & 0.1 & 0.1 & 0.14 & 0.14 \\
\hline
\end{tabular}

\section{Experimental Results and Analysis}

\subsection{Experiments to select spray parameters}

Table 3 and Fig.5 show the results of average peak-to-valley cutting forces for four different combinations of the spray parameters. As seen in Fig. 5, the cutting forces for spray conditions $\mathrm{T} 1$ and $\mathrm{T} 4$ are lower than that for $\mathrm{T} 2$ and $\mathrm{T} 3$. As reported in Hoyne et al.[16], the reduction in cutting force is observed when the liquid film is stable and penetrates the cutting zone. Thus, it is possible that the liquid film formed at $\mathrm{T} 1$ and $\mathrm{T} 4$ spray conditions has ideal thickness and momentum to reach the cutting interface.

Table 3: Experimental results for different combinations of spray conditions

\begin{tabular}{|c|c|c|c|c|c|c|c|c|c|c|}
\hline \multirow{3}{*}{ Test } & \multirow{3}{*}{$\begin{array}{l}\text { Spray } \\
\text { dis- } \\
\text { tance, } \\
\mathrm{x}_{1}[\mathrm{~mm}]\end{array}$} & \multirow{3}{*}{$\begin{array}{l}\text { Pressure, } \\
\mathrm{x}_{2}[\mathrm{psi}]\end{array}$} & \multicolumn{8}{|c|}{ Avergae peak-to-valley cutting forces $[\mathrm{N}]$} \\
\hline & & & \multicolumn{2}{|c|}{ Run1 } & \multicolumn{2}{|c|}{ Run2 } & \multicolumn{2}{|c|}{ Run3 } & \multicolumn{2}{|c|}{ Average } \\
\hline & & & Feed & $\begin{array}{l}\text { Cross- } \\
\text { Feed }\end{array}$ & Feed & $\begin{array}{l}\text { Cross- } \\
\text { Feed }\end{array}$ & Feed & $\begin{array}{l}\text { Cross- } \\
\text { Feed }\end{array}$ & Feed & $\begin{array}{l}\text { Cross- } \\
\text { Feed }\end{array}$ \\
\hline $\mathrm{T} 1$ & 40 & 9 & 116 & 67 & 117 & 68 & 116 & 67 & 116.3 & 67.3 \\
\hline $\mathrm{T} 2$ & 60 & 9 & 123 & 71 & 123 & 71 & 123 & 71 & 123 & 71 \\
\hline T3 & 40 & 15 & 127 & 73 & 128 & 74 & 126 & 71 & 127 & 72.6 \\
\hline $\mathrm{T} 4$ & 60 & 15 & 118 & 68 & 119 & 69 & 119 & 69 & 118.6 & 68.6 \\
\hline
\end{tabular}

In order to understand the liquid film penetration to the cutting zone for different combinations of spray parameters, numerical simulations using the 


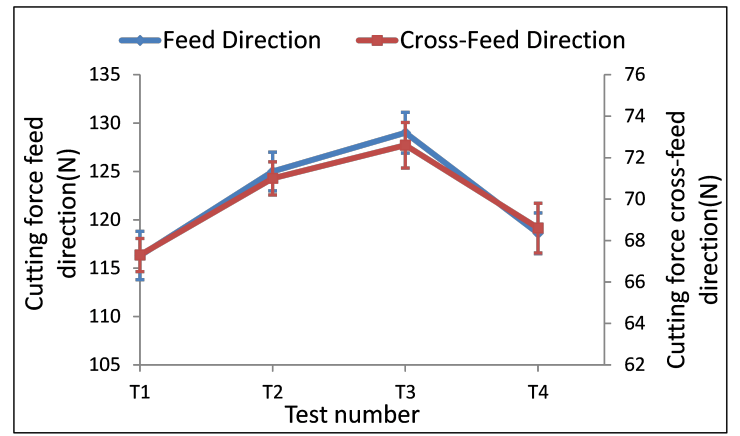

Figure 5: Cutting forces for different combinations of spray conditions

CFD approach have been conducted to study the film formation by the ACF spray system on a rotating surface. Two numerical models, namely, ACF spray model and film formation model, have been developed. In the spray model, discrete phase modeling (DPM) approach is used for tracking the liquid droplets in the domain and the film formation model employs the eulerian wall film (EWF) approach for modeling the liquid film formation on a rotating surface.

A 2-dimensional (2D) schematic of the geometry used in the numerical model is shown in Fig. 6. The rotating end-mill tool has been modeled as a cylinder. The wall of the cylinder is assumed to be smooth and the cylinder has a fixed angular velocity. More detailed information about the numerical model can be found in [17]. To characterize the liquid film for different combinations of

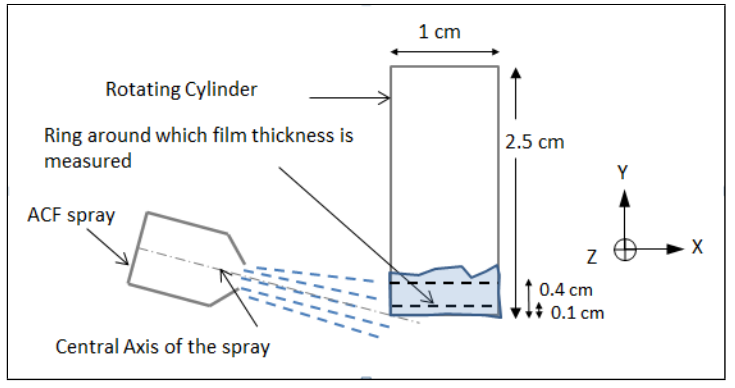

Figure 6: 2D view of the geometry used for simulations

spray parameters, liquid film thickness along the circumference of the cylinder, 
rotating at an angular velocity of 1500 RPM, has been evaluated. Figure 7 shows the 3-D plot of liquid film thickness for T4 spray condition. As seen in Fig. 7 the liquid film thickness varies considerably near the point of impact of the spray but stabilizes at distances father away from it. Thus, an average of computed

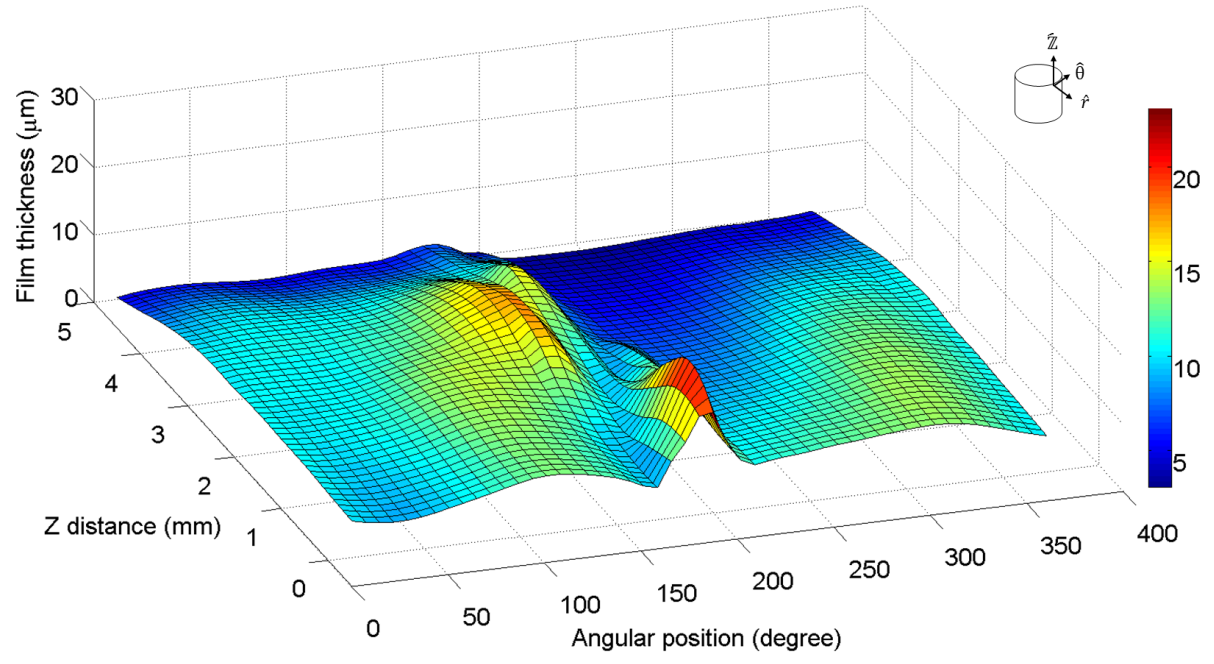

Figure 7: 3-D plot of the film formed on the rotating cylindrical surface

film thicknesses at distances of $0.2,0.3$ and $0.4 \mathrm{~cm}$ from the base of the cylinder have been used to estimate the steady state values of film thicknesses and are shown in Fig. 8. The average film thickness over the entire circumference of the cylinder has also been calculated. For spray conditions, T1, T2, T3 and T4, the average film thickness over the circumference of the cylinder are: 7.3, 10.1, 4.2 and $8.1 \mu \mathrm{m}$, respectively. As seen from Fig. 8, the average film thickness for spray condition T2 (spray distance: $60 \mathrm{~mm}$, carrier gas inlet pressure: $9 \mathrm{psi}$, droplet velocity: $14 \mathrm{~m} / \mathrm{s}$ ) is the largest and for T3 condition (spray distance: $40 \mathrm{~mm}$ and carrier gas inlet pressure: $15 \mathrm{psi}$, droplet velocity: $33 \mathrm{~m} / \mathrm{s}$ ) it is the smallest among the four different combinations of spray parameters. Note that for T3 condition, the droplet velocity is $33 \mathrm{~m} / \mathrm{s}$, which is much higher than the droplet velocity of $14 \mathrm{~m} / \mathrm{s}$ at T2. Thus, it can be inferred that higher droplet velocities lead to the formation of thinner fluid films and lower velocities lead to thicker fluid film, which is in agreement with the results obtained by Kalantari 
et al. [18].

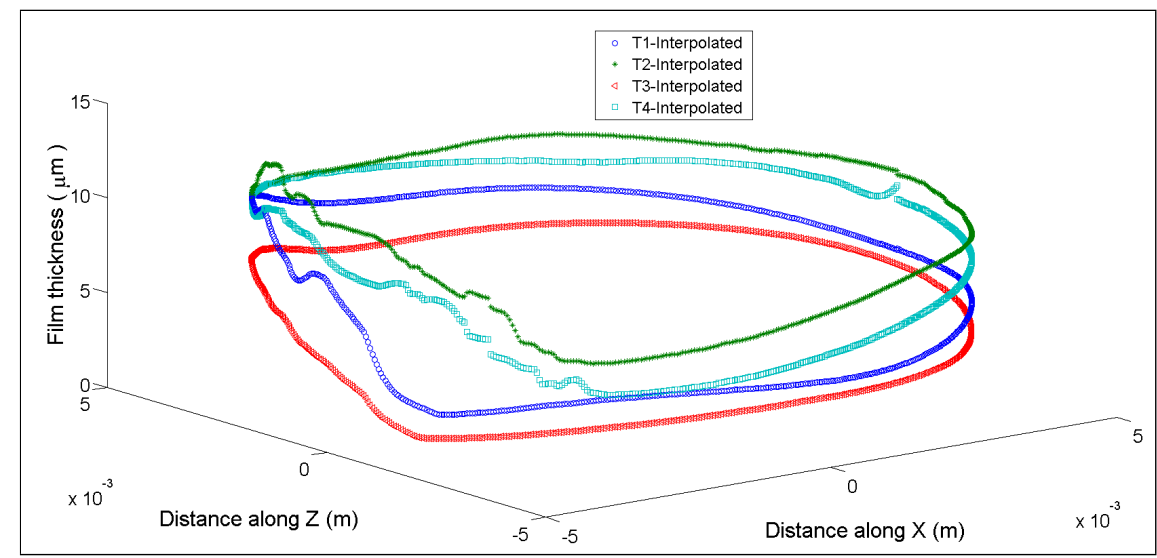

Figure 8: 3D plot of film thickness as a function of angular position for all conditions.

When the liquid film thickness is $4.2 \mu \mathrm{m}$, it is possible that it could get evaporated even before reaching the cutting zone and little or no liquid would be present for providing lubrication at the cutting interface. Similarly, the liquid film for spray condition T2, having a film thickness of $10.1 \mu \mathrm{m}$, might not have enough momentum to reach the cutting zone, thereby resulting in the production of high cutting forces. For other spray conditions, the liquid film thickness is adequate enough so that the spreading liquid film is able to access the cutting zone and provide substantial cooling and lubrication. As a result, as seen in Fig. 5, the cutting forces for $\mathrm{T} 1$ and $\mathrm{T} 4$ conditions are lower than those for $\mathrm{T} 2$ and $\mathrm{T} 3$ conditions.

4.2. Experiments to evaluate machinability of titanium alloy in milling using the ACF spray system

\subsubsection{Tool life}

Figure 9 illustrates the progress of tool flank wear at machining condition M1, as listed in Table 2, for different cutting fluid application methods. The spray parameters are chosen according to condition T4 (Table 1). It is seen 
from Fig. 9 that the tool life extends by $75 \%$ over flood cooling. Since in the ACF spray system the droplet carrier gas accelerates and imparts momentum to the micro-sized droplets, a thin liquid film is formed and this spreading film is able to penetrate the tool-chip interface. As a result, Sulphur, an additive in $10 \%$ S-1001, at high temperatures chemically reacts with the freshly generated metal surfaces of the chip and produces a metallic sulfide film that has lower shear strength than the chip material. This causes a reduction in friction, which further leads to reduction in temperature of the cutting zone[19]. Further, thin liquid film is able to remove heat from the cutting zone by evaporative cooling whereas the low temperature and high velocity of the droplet carrier gas provides forced convective cooling of the cutting zone. The combined action of these two cooling mechanisms lowers the temperature of the cutting zone significantly. Dry cutting offers the least amount of tool life among the cutting fluid application methods evaluated in this study and fails after 4.1 min of machining.

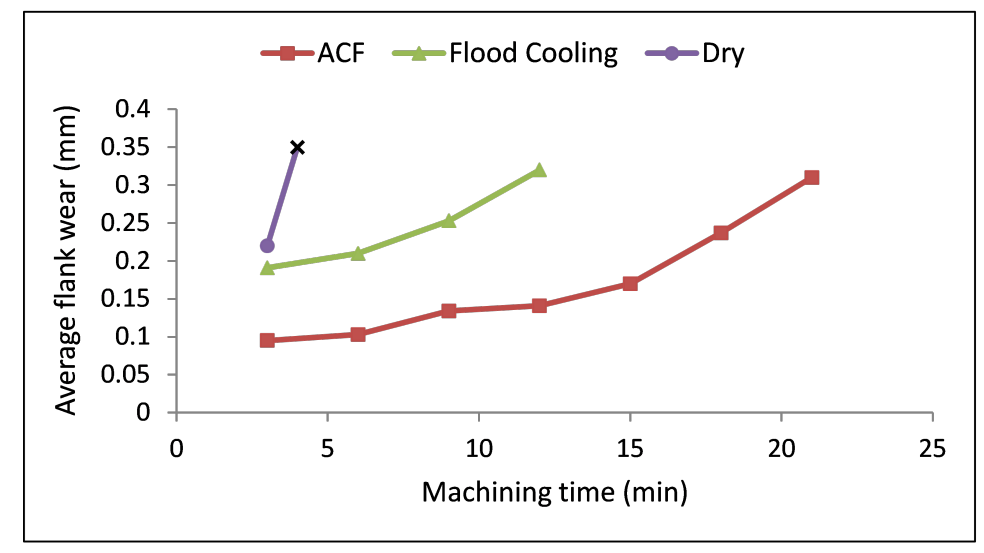

Figure 9: Wear progress of the tool flank with machining for different cutting fluid application methods

\subsubsection{Tool wear}

Figures 10-12 show the tool flank wear for two out of the four diametrically opposite flutes of the end mill at the time of tool failure. It is seen that max- 
imum flank wear that occurs at the nose is the controlling factor of tool life. Figure 10 shows that with the application of the ACF system, the tool wear is uniform, without any abrupt chipping and notch formation. The presence of groove on the flank face and shiny flank wear are indicative of the attritional wear mechanism that takes place when the cutting zone temperature is not very high[20]. Attritional wear leads to uniform wear of both the carbide particles and binder material in the tool. Figure 12 shows that the tool fails catastrophically by cutting edge chipping and notch formation when flood cooling cutting condition is used. Predominant wear mechanism for such type of wear is abrasion, which takes place at high cutting temperatures. During abrasive wear, the high temperatures at the cutting zone increases the wear rate of binder material in tool as compared to the carbide particle. As a result the carbide particles keep sticking out of the tool. Edge chipping and notch wear indicate that flood cooling is not able to effectively cool and lubricate the cutting interfaces. Under dry cutting conditions the tool fails catastrophically because of excessive chipping of the flank surface, as shown in Fig. 11. The significant discoloration of the flank surface of the tool is indicative of the presence of high temperatures near the cutting zone that lead to oxidation of the flank surface and plastic deformation of the tool.

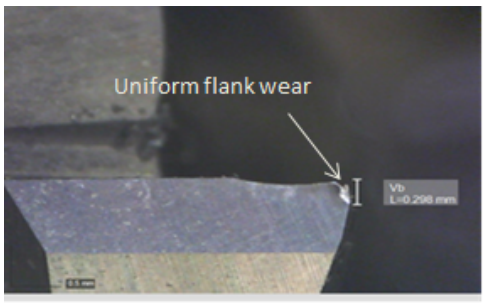

(a) Flute 1

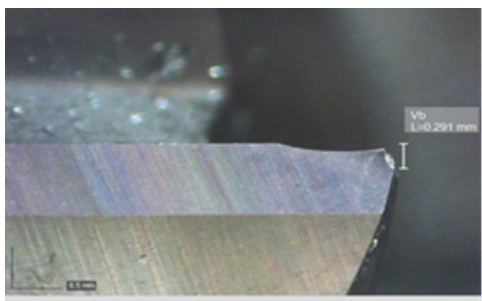

(b) Flute 2

Figure 10: Tool flank face when using the ACF spray system 


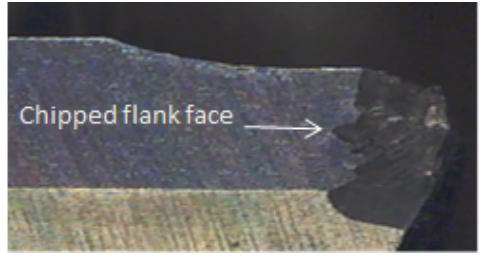

(a) Flute 1

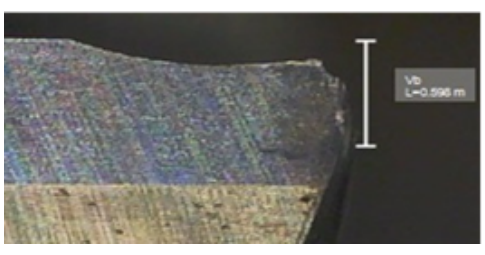

(b) Flute 2

Figure 11: Tool flank face when using dry cutting conditions

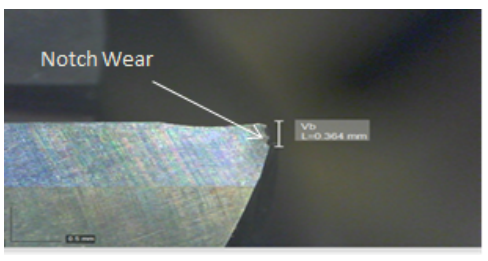

(a) Flute 1

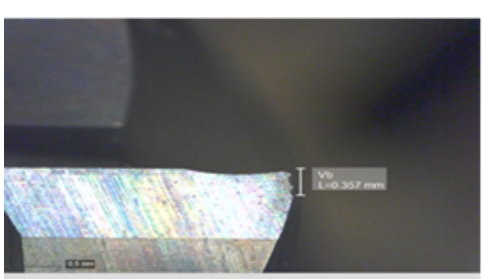

(b) Flute 2

Figure 12: Tool flank face when using flood cooling

\subsubsection{Chip morphology}

Further evidence of greater cooling capability of the ACF spray system over flood cooling can be found by studying the chips that are collected during endmilling titanium alloy. Figure 13 shows the collected chips for machining condition M1, when ACF and flood cooling conditions are used. The chips have an average length of $3 \mathrm{~mm}$ and thickness of $0.18 \mathrm{~mm}$ when using the ACF spray system, whereas those collected under flood cooling condition have an average length of $5 \mathrm{~mm}$ and thickness of $0.17 \mathrm{~mm}$. On average, the chips produced when machining with the ACF spray system are found to be shorter in length as compared to chips that are generated using flood cooling. The broken chips are probably due to the increase in brittleness of the produced chips as a result of excellent cooling capabilities of the ACF spray system [5]. 


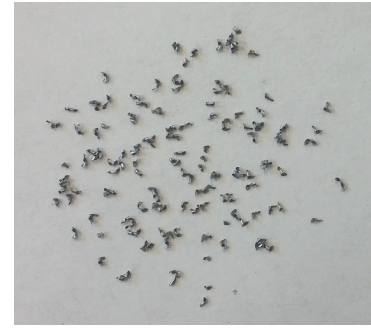

(a) ACF spray system

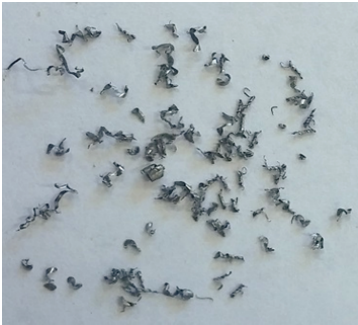

(b) Flood cooling

Figure 13: Chip morphology when machining at M1

\subsubsection{Effect of $\mathrm{CO}_{2}$ presence in the carrier gas mixture on tool life}

In order to evaluate the effect of presence of $\mathrm{CO}_{2}$ in the gas mixture of the ACF spray system on the tool life, experiments are conducted with and without $\mathrm{CO}_{2}$ (only air in the droplet carrier gas). Figure 14 shows the average flank wear using the ACF spray system, with and without the presence of $\mathrm{CO}_{2}$ in the carrier gas. It is seen from Fig. 14 that the tool life is $33 \%$ lesser than what would have been obtained had $\mathrm{CO}_{2}$ been present in the gas mixture. It can also be seen from Fig.15 that the absence of $\mathrm{CO}_{2}$ and presence of only air in the droplet carrier gas has the undesirable effect of chipping of cutting edges due to the presence of high temperatures in the cutting zone that increases the tool abrasion. Note that, even in the absence of $\mathrm{CO}_{2}$ from the gas mixture, the tool life is $17 \%$ more as compared to flood cooling because of effective penetration capabilities of atomized droplets in the cutting zone.

\subsubsection{Cutting force}

Figure 16 a-c shows the variation of cutting force for different machining conditions, M1-M4, when using the ACF spray system. It is seen from Fig. 16 that the cutting forces are the smallest for the machining condition M1. However, the rate of increase in cutting forces is higher with the increase in feed rate than by an increase in ADOC alone. When the feed rate is high, the 


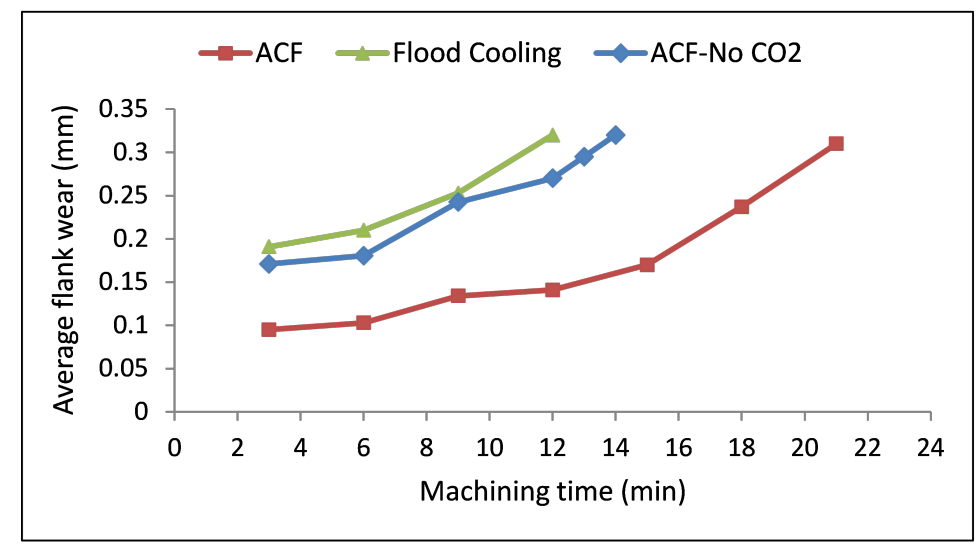

Figure 14: Wear progress of the tool flank for different cutting fluid application methods [Machining Condition: $1500 \mathrm{RPM}, \mathrm{ADOC}=0.5 \mathrm{~mm}, \mathrm{RDOC}=2 \mathrm{~mm}, \mathrm{FR}=0.1 \mathrm{~mm} /$ tooth]

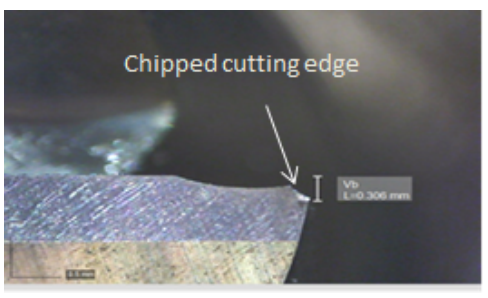

(a) Flute 1

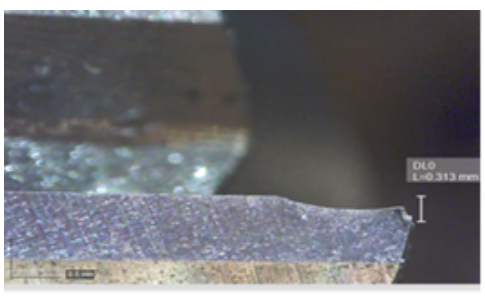

(b) Flute 2

Figure 15: Tool flank face when using the ACF spray system and no $\mathrm{CO}_{2}$ 
cutting zone experiences higher temperatures, due to larger chip load, than what it would be for lower feed rates. The liquid film formed on the tool might not be sufficient and it would evaporate, owing to high temperatures, even when the cutting edge is engaged with the tool. As a result the cooling and lubrication is not effective in this situation, leading to higher cutting forces.

Figure $17 \mathrm{a}-\mathrm{c}$ shows a comparison of the cutting forces when machining a titanium alloy using different cutting fluid application methods. Note that the first cutting force data has been recorded at 0.25 min from the start of machining. As seen from the Fig. 17, the cutting forces using the ACF spray system are generally lower than the other cutting fluid application methods. However, except for dry cutting, where the rise in cutting forces is steep, for all the other cutting fluid application methods the cutting forces for the first three minutes are almost the same. A possible reason could be that during the initial stages of machining the temperature rise in the cutting zone is small because of sharp cutting edges of the tool and cooling and lubrication provided by the cutting fluid. However, with increase in time the tool wears out and the temperature rise and friction in the cutting zone become significant leading to higher cutting forces. As seen in Fig. 17, the ACF spray system is able to provide the most effective cooling and lubrication, which is instrumental in reducing the rate of flank wear and the cutting forces.

\subsubsection{Surface roughness}

Figure 18 (a)-(b) shows the average and maximum surface roughness when using different cutting fluid application methods. Figure 18 shows that the surface roughness obtained when using flood cooling and ACF system are almost comparable for the first $7.5 \mathrm{~min}$ of machining. However, after $7.5 \mathrm{~min}$, the surface quality of the machined surface deteriorates rapidly for flood cooling. Under dry cutting conditions, the cutting edges experience intensive stresses and temperatures that accelerate the rate of flank wear, as seen in Fig. 9, resulting 


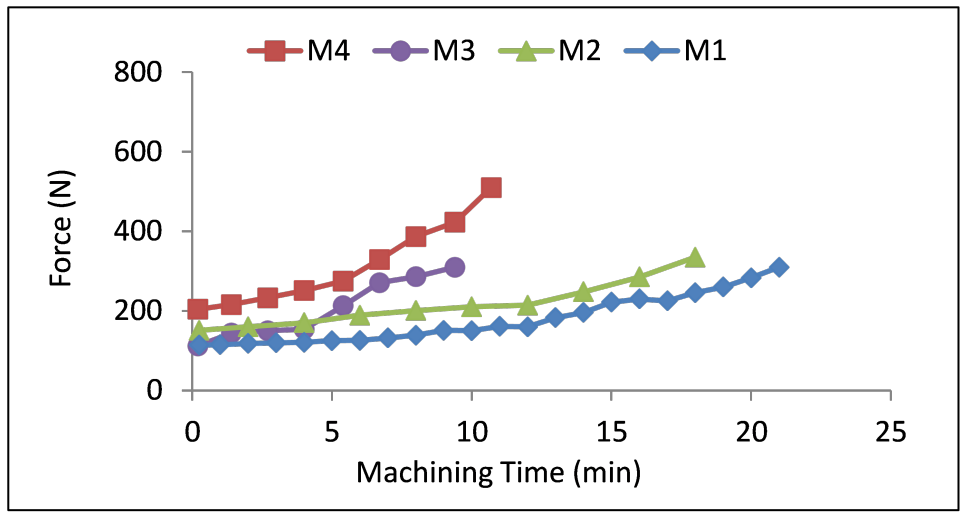

(a) Feed Direction

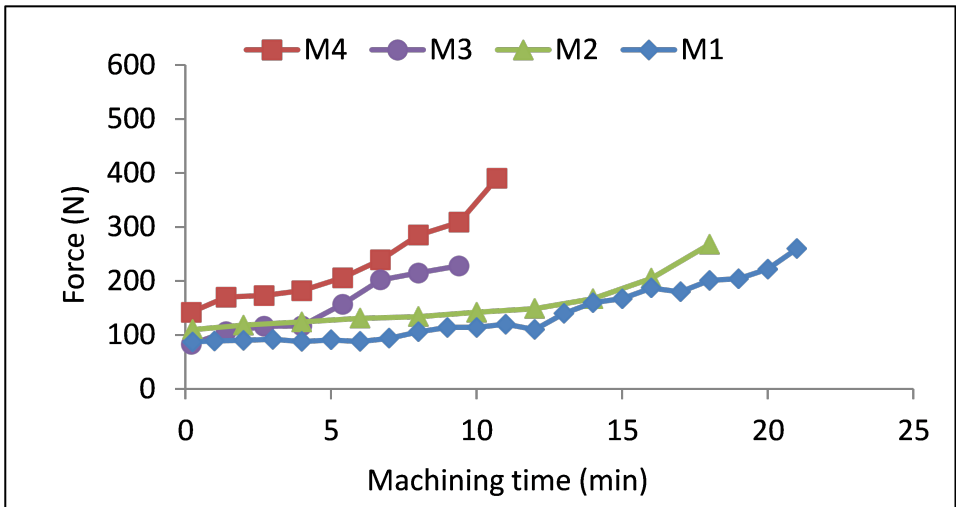

(b) Cross-feed direction

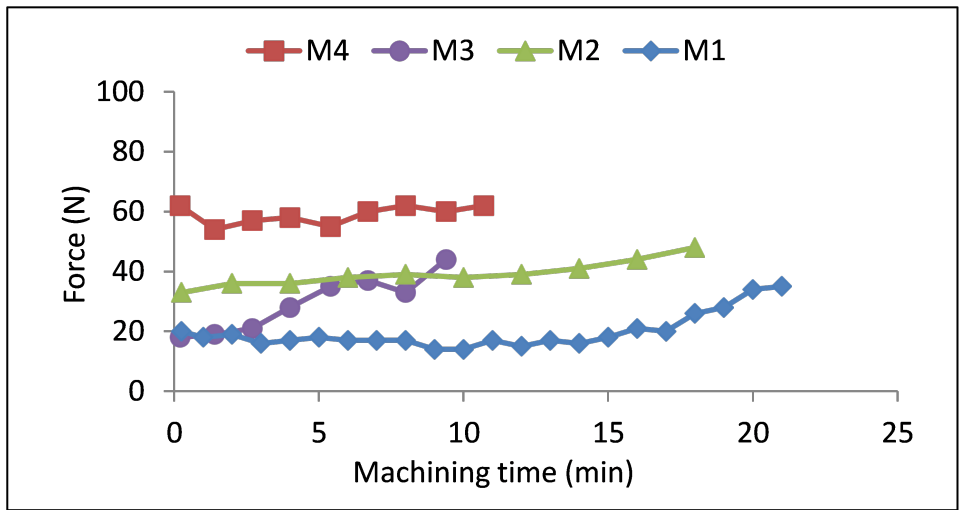

(c) Z direction

Figure 16: Variation of cutting forces for different machining conditions with the ACF spray system 


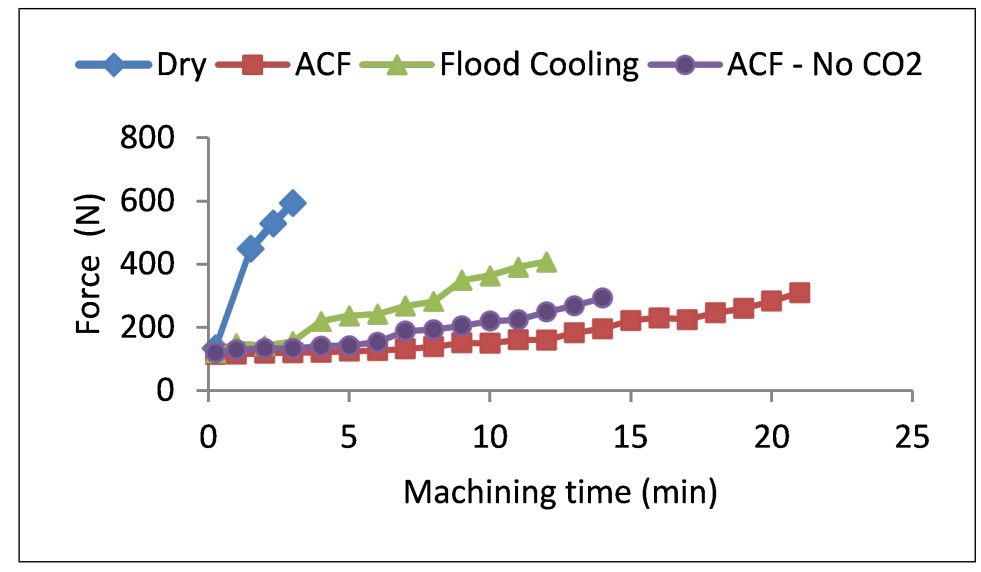

(a) Feed Direction

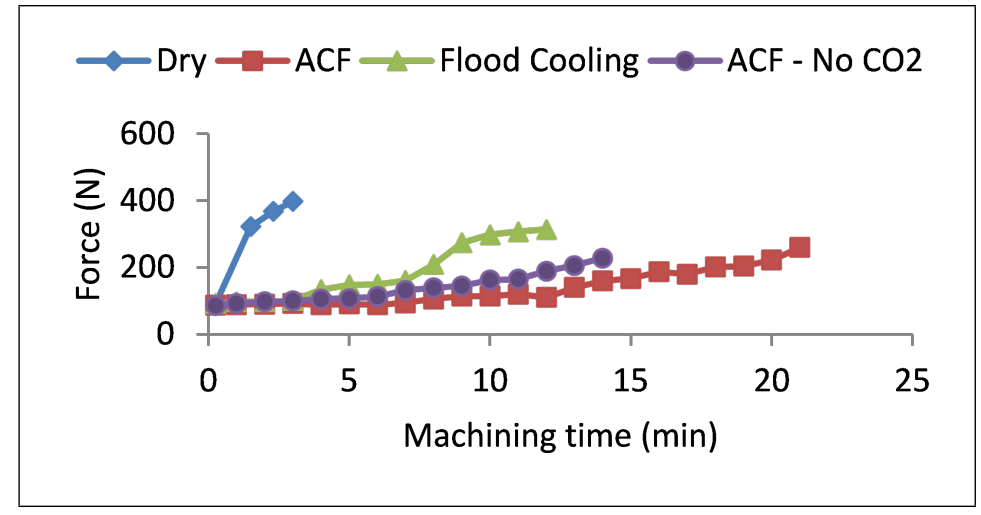

(b) Cross-feed direction

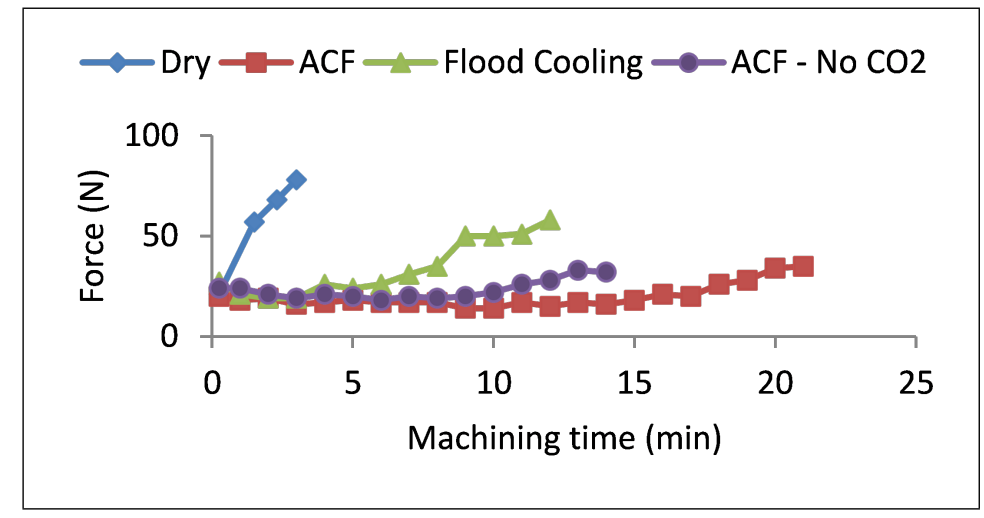

(c) Z direction

Figure 17: Variation of cutting forces for different cutting fluid application methods [ Machining Condition: $1500 \mathrm{RPM}, \mathrm{ADOC}=0.5 \mathrm{~mm}, \mathrm{RDOC}=2 \mathrm{~mm}, \mathrm{FR}=0.1 \mathrm{~mm} /$ tooth ] 
in higher values of surface roughness. A probable cause of difference between the surface finish obtained by ACF spray system and flood cooling is that the application of latter method eventually leads to notch formation on the cutting edges, as seen in Fig. 12, which leads to a sudden increase in surface roughness, whereas the application of ACF spray system leads to lower and steady flank wear. As a result the surface roughness increases slowly with time for the ACF spray system.

Figure 19(a) shows the average and maximum surface roughness obtained using ACF spray system for four different machining conditions. It is observed that similar to cutting forces, the average and maximum surface roughness are also dependent upon the machining conditions, especially, the feed rate plays a significant role as compared to ADOC in determining the surface finish.

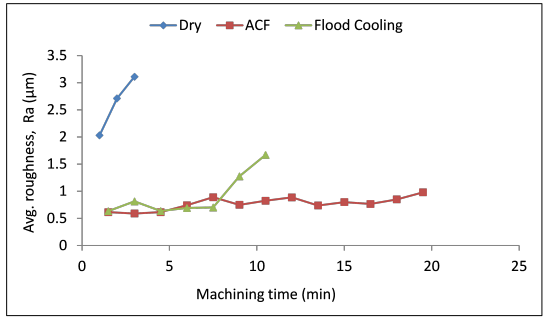

(a)

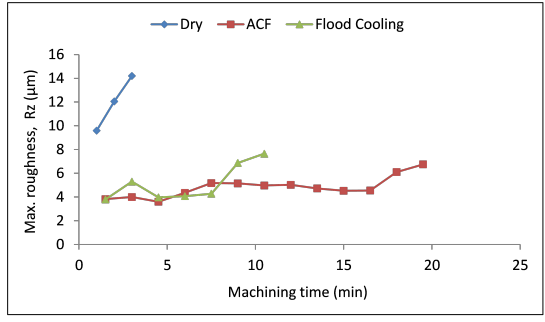

(b)

Figure 18: (a) Average (b) maximum surface roughness values for different cutting fluid application method at machining condition M1

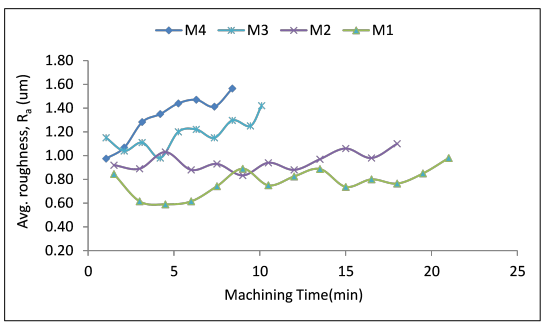

(a)

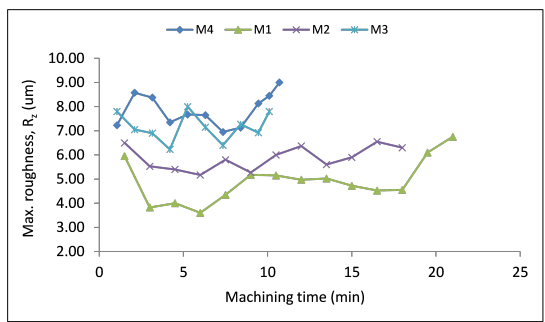

(b)

Figure 19: a) Average (b) maximum surface roughness values for different machining conditions with the ACF system 


\section{Conclusions}

The atomization-based cutting fluid spray system has been evaluated for end-milling of titanium alloy, Ti-6Al-4V. Experiments were conducted to not only study the effect that the variation of ACF spray parameters has on the measured cutting forces but also to compare the performance of the ACF spray system to that of other cutting fluid application methods, viz., flood cooling and dry cutting. The following conclusions are drawn from this work:

1. The cutting forces are influenced by the ACF spray system parameters. The numerical model of the liquid film formation when droplets from the ACF spray impinges on the rotating tool suggests that for certain ACF system spray parameters the liquid film has sufficient momentum to reach the cutting zone and provide cooling and lubrication thereby resulting in reduced cutting forces.

2. ACF spray system is able to extend the tool life as high as $75 \%$ over flood cooling when the feed/tooth and axial depth of cut values are chosen as $0.1 \mathrm{~mm} /$ tooth and $0.5 \mathrm{~mm}$, respectively.

3. When comparing the use of $\mathrm{CO}_{2}$ in the droplet carrier gas of the ACF spray system, it is observed that the tool life increases by $50 \%$ when the droplet carrier gas is a mixture of air and $\mathrm{CO}_{2}$ as compared to the case where droplet carrier gas has only air.

4. With ACF spray application method, the cutting edges undergo uniform wear and the tool does not fail catastrophically due to attritional wear caused by lower temperatures of the cutting edges. On the other hand when dry and flood cooling cutting conditions are used, the tool wears out rapidly and undergoes catastrophic failure because of chipping and notch formation on the tool flank face.

5. The length of the chips generated with the ACF spray system is shorter than those that are generated with flood cooling. 
6. Enhanced cooling and lubrication capabilities of ACF spray system, due to thin film formation on the cutting edge was instrumental in reducing the tool flank wear and hence the cutting forces and surface finish.

\section{Acknowledgments}

The authors would like to gratefully acknowledge the financial support of the National Science Foundation grant no. NSF-CMMI-12-33944 and TechSolve, Inc., Cincinnati, OH. The authors would also like to thank Dr. Chandra Nath and Soham Mujumdar for helping with the experimental setup.

\section{References}

[1] E. Ezugwu, Z. Wang, Titanium alloys and their machinability - a review, Journal of Materials Processing Technology (1995) 262-274.

[2] N. Courduan, T. Himbert, G. Poulachon, M. Dessoly, M. Lambertin, J. Vigneau, B. Payoux, Wear mechanisms of new tool materials for ti-6al-4v high performance machining, CIRP Annals - Manufacturing Technology $52(2003) 73-76$.

[3] N. Narutaki, A. Murakoshi, S. Motonishi, H. Takeyama, Study on machining of titanium alloys, CIRP Annals - Manufacturing Technology 32 (1983) $65-69$.

[4] S. ZHANG, L. Jian-feng, Tool wear criterion, tool life, and surface roughness during high-speed end milling ti-6al-4v alloy, Journal of Zhejiang University-SCIENCE A (Applied Physics \& Engineering) 11 (2010) 587595.

[5] C. Nath, S. G. Kapoor, R. E. DeVor, A. K. Srivastava, J. Iverson, Design and evaluation of an atomization-based cutting fluid spray system in 
turning of titanium alloy, Journal of Manufacturing Processes 14 (2012) 452-459.

[6] T. Thepsonthi, M. Hamdi, K. Mitsui, Investigation into minimal-cuttingfluid application in high-speed milling of hardened steel using carbide mills, Investigation into minimal-cutting-fluid application in high-speed milling of hardened steel using carbide mills 49 (2009) 156-162.

[7] X. J. Cai, Z. Q. Liu, M. Chen, Q. L. An, An experimental investigation on effects of minimum quantity lubrication oil supply rate in high-speed end milling of ti-6al-4v, Proceesings of the Institution of Mechanical Engineers, Part B: Journal of Engineering Manufacture 0 (2012) 1-9.

[8] Y. Su, N. He, L. Li, X. Li, An experimental investigation of effects of cooling/lubrication conditions on tool wear in high-speed end milling of ti-6al-4v, Wear 261 (2006) 760-766.

[9] M. B. Jun, S. S. Joshi, R. E. DeVor, S. G. Kapoor, An experimental evaluation of an atomization-based cutting fluid application system for micromachining, Journal of Manufacturing Science and Engineering 130.

[10] I. Ghai, J. Wentz, R. E. DeVor, S. G. Kapoor, J. Samuel, Droplet behavior on a rotating surface for atomization-based cutting fluid application in micromachining, Journal of Manufacturing Science and Engineering 132.

[11] K. J. Boughner, J. E. Wentz, B. J. Garske, Development and validation of a mathematical model of microfilm formation in atomization cooling of micromachining, Denver, 2011.

[12] C. Nath, S. G. Kapoor, A. K. Srivastava, J. Iverson, Effect of fluid concentration in titanium machining with an atomization-based cutting fluid (acf) spray system, Journal of Manufacturing Processes 15 (4) (2013) 419 - 425. doi:http://dx.doi.org/10.1016/j.jmapro.2013.06.002. 
[13] M. Trujillo, W. Mathews, C. Lee, J. Peters, Modelling and experiment of impingement and atomization of a liquid spray on a wall, International Journal of Engine Research 1 (2000) 87-105.

[14] L. Lopez de Lacalle, C. Angulo, A. Lamikiz, J. Sanchez, Experimental and numerical investigation of the effect of spray cutting fluids in high speed milling, Journal of Material Processing Technology 172 (2006) 11-15.

[15] ISO, http://www.iso.org/iso/catalogue_detail.htm?csnumber= 16092/, [Online; accessed 1989] (1989).

[16] A. Hoyne, C. Nath, S. Kapoor, Characterization of fluid film produced by an atomization-based cutting fluid spray system during machining, Journal of Manufacturing Science and Engineering 135.

[17] S. Ganguli, Evaluation of the atomization-based cutting fluid spray system in milling of titanium alloy, Master's thesis, University of Illinois at Urbana Champaign (8 2015).

[18] Spray impact onto flat and rigid walls: Empirical characterization and modelling, International Journal of Multiphase Flow 33 (5) (2007) 525 544. doi:http://dx.doi.org/10.1016/j.ijmultiphaseflow.2006.09.008.

[19] T. J. Drozda, C. Wick (Eds.), Tool and Manufacturing Engineers Handbook: Volume 1 Machining, 4th Edition, Society of Manufacturing Engineers, 1983.

[20] J. Gu, G. Barber, S. Tung, R.-J. Gu, Tool life and wear mechanism of uncoated and coated milling inserts, Wear 225-229 (1999) 273-284. 